\title{
The research progress on method of preparation of biomass charcoal and modification
}

\author{
H.H. LI ${ }^{1, a} ;$ M.N. LIANG ${ }^{1, b,{ }^{*}} ;$ S. TAN ${ }^{1} ;$ Y.M. QIN ${ }^{1} ;$ L. ZHU ${ }^{1}$ \\ ${ }^{1}$ College of Environmental Science and Engineering, Guilin University of Technology, Guilin 541004, \\ P.R. China \\ alihuan201211@126.com, ${ }^{b}$ liangmeinaa@163.com
}

*Corresponding author: Liang Mei-Na, tel: 0773-3693255; E-mail address: liangmeinaa@163.com.

Keywords: Biomass; activated carbon; preparation method; modification method

\begin{abstract}
As a new environmental friendly material, the preparation and modification of biomass charcoal has become more and more popular in environmental science and other research field. Preparation techniques and the mechanism of activation of various methods were introduced in this paper. Carbonization and activation were two key classical methods to prepare biomass activated carbon. Now activated carbon was modified by changing the physical properties of surface structural, surface chemical and electrochemical properties. Electrochemical modification method would be the most prospective. Some ideas were provided to promote the application of biochar.
\end{abstract}

\section{Introduction}

Based on activated carbon having a rich porosity and having a high specific surface area, it is widely used adsorbents for water purification. But in recent years, the high production costs restricted the application and development of activated carbon, there have been many studies focused on how to prepare high surface area activated carbon by using inexpensive and readily available biomass waste energy ${ }^{[1,4]}$. Waste biomass as a cheap raw material to prepare activated carbon, it can solve the problem of disposal biomass waste, improved resource recycling value. L.G. Liu, et al. ${ }^{[2]}$ researched chestnut shell as materials to prepare activated carbon, they selected $\mathrm{ZnCl}_{2}$ as activator and got activated carbon, which specific surface area was $980 \mathrm{~m}^{2} / \mathrm{g}$. B. Han, et al. ${ }^{[3]}$ also researched rice straw as raw material, the resulting specific surface area of activated carbon was $1078.21 \mathrm{~m}^{2} / \mathrm{g}$. B. Li, et al. ${ }^{[5]}$ research Long handle almond shells as raw materials for preparing activated carbon, using zinc chloride activation method to prepare specific surface area of 1633.08 $\mathrm{m} 2 / \mathrm{g}$ activated carbon.

However, as more and more polymers, chemical synthetic products are widely applied in various fields, due to the poor selection of adsorption properties, ordinary activated carbon has limited ability to remove pollutants, it has been unable to meet market demand at domestic and abroad. Therefore, it is necessary for ordinary activated carbon to modify, to improve the adsorption capacity on the different pollutants, and improve its sewage treatment effect. Currently, the modified activated carbon are widely used in sewage treatment, air pollution control, soil remediation and other fields, especially in terms of water pollution control, showing a good development prospects.

\section{The raw materials}

Activated carbon is a well-known excellent adsorbent; its raw materials are mainly plant and mineral type two categories. Some plant-based raw materials include scrap wood, husk, bagasse, and bamboo, crop straw and other ${ }^{[6,7]}$. Using these plant-based raw materials having natural structure can get activated carbon having developed pore, large surface area and high mechanical strength. Minerals raw materials are: coal, petroleum coke, petroleum bitumen and synthetic resins, etc. In all of these raw materials, the most abundant genera are coal resources, but the structure and the characteristics of composition of coal itself, those have a direct impact on the performance of 
activated carbon, and it is difficult to develop a microporous activated carbon. Preparation of activated carbon, based on different raw materials the activation process conditions will be different, generally based on the selection of raw materials to select the optimum conditions for preparing activated carbon ${ }^{[8]}$. The study found that the physical and chemical properties of biomass charcoal under different sources as well as different prepared conditions are different, the adsorption capacity are also different ${ }^{[9,10]}$.

\section{The research on preparation method of biomass activated carbon}

The process of preparation of activated carbon includes two procedures: an inert gas (usually with $\mathrm{N}_{2}$ ) when one will be carbonized, carbonized charcoal raw materials for protection; the second is the charcoal-activated ${ }^{[11,12]}$.

\section{Carbonization}

Carbonization refers to hypoxic conditions at a high temperature, the raw material in the pyrolysis of organic matter, in order to obtain more holes in the carbon structure, divided into a thermal decomposition reaction and condensation reaction. In the carbonization process, most of the non-carbon elements (such as hydrogen and oxygen, etc.) are removed as a volatile component; while charring product as a combination of carbon atoms an aromatic ring, which the sheet structure is very irregular, there are some cracks exist during activation, these cracks will form a developed porous structure.

Carbonization temperature has a great influence on the pore structure of plant-based charcoal size and specific surface area. Carbonization temperature is generally from $300^{\circ} \mathrm{C}$ to $1000 \mathrm{p} \mathrm{e}^{14]}$, charring occurs very intense phase thermal decomposition reaction, the molecular chain of C-O, $\mathrm{C}-\mathrm{C}$ bond fracture ${ }^{[15]}$. When the carbonization temperature is high, carbonized material particles become real, porosity decreases, not conducive to the activation reaction; while charring temperature is low, the formation of small crystallites, pores are more conducive to the activation reaction, but the particles apparent density decreases, the mechanical strength is lowered. Under certain carbonization temperature, to ensure sufficient holding time to ensure adequate raw material carbonization process, in order to avoid inadequate internal charring of the material.

\section{Activation}

Activation is aimed at using gas or chemicals to change the internal pore structure of carbonized material, expanding its surface area, improving the adsorption capacity of activated carbon. Activation reaction generated carbonized material during activation with low oxidizing gases (such as water vapor, carbon dioxide, air, etc.) of physical reactions and chemical reactions ${ }^{[16]}$. At present, the commonly used method of physical activation activation, chemical activation method and chemical physical activation method ${ }^{[17,18]}$.

\section{Physical activation method}

Physical activation method refers to a certain temperature, using an appropriate oxidizing gases (carbon dioxide, water vapor, etc.) react with the carbon atom "active site" of carbonized material on the inside surface of the material developed pore structure ${ }^{[19]}$. The physical preparation of activated carbon, the process is simple, and belongs to cleaner production, the activated carbon does not need to be cleaned, it can be applied directly. Physical activation method is basically suitable for the production process for the preparation of activated carbon using all carbonaceous material, the activated carbon producted has developed pore and good physical properties (such as having good physical strength). Therefore, physical activation methods attract a growing number of researchers into their research work.

K.B. Yang, et al. ${ }^{[20]}$ used coconut shell as raw materials, it is carbonized for $2 \mathrm{~h}$ under carbonization temperature of 600

i̊ecthe@ $\mathrm{O}_{2}$ as activator of preparing activated carbon, the iodine adsorption of coconut shell-based activated carbon is $1428.00 \mathrm{mg} / \mathrm{g}$, the specific surface area, the total pore volume and pore volume were $1653 \mathrm{~m}^{2} / \mathrm{g}, 1.045 \mathrm{~cm}^{3} / \mathrm{g}$ and $0.8582 \mathrm{~cm}^{3} / \mathrm{g}$, respectively. 
Sun, et al. ${ }^{[21]}$ Used the pods as raw material, using steam activation to prepare a activated carbon of the specific surface area of $948 \mathrm{~m}^{2} / \mathrm{g}$. Sahin, et al. ${ }^{[22]}$ used $\mathrm{ZnCl}_{2}$ and $\mathrm{HCl}$ the two-step pretreatment step to pretreat the raw materials, re-using water steam- $\mathrm{CO}_{2}$ mixed activation system, at $850^{\circ} \mathrm{C}$ conditions, preparing the activated carbon, the resulting specific surface area of activated carbon was $1779 \mathrm{~m}^{2} / \mathrm{g}$.

\section{Chemical activation method}

Chemical activation method means the raw material with an activator by mixing, impregnating for a period of time, under the protection of an inert gas atmosphere, carbonization and activation synchronously complete ${ }^{[23]}$.Commonly used chemical activators as following, inorganic salts and some acids, $\mathrm{KOH}^{[24]}, \mathrm{NaOH}, \mathrm{ZnCl}_{2}, \mathrm{H}_{3} \mathrm{PO}_{4}{ }^{[25]}$ are used more often, among them, the performance of the preparation of activated carbon with $\mathrm{KOH}$ as activator is most outstanding ${ }^{[26]}$. K. Sun, et al. ${ }^{[27]}$ used the abandoned bamboo as raw material, by $\mathrm{KOH}$ activation prepared the high specific surface area of activated carbon, get BET specific surface area of $2938 \mathrm{~m}^{2} / \mathrm{g}$ of activated carbon, its iodine adsorption value of is up to $2049 \mathrm{mg} / \mathrm{g}$, the adsorption of methylene blue is $570 \mathrm{mg} / \mathrm{g}$.

Chemical activation compared with the physical activation method, its advantages are: (1) low

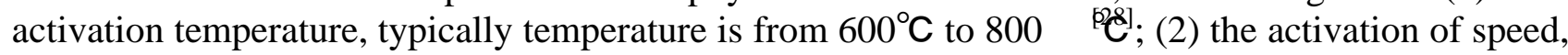
low power consumption;(3) it has developed pore structure and higher levels of surface functional groups ${ }^{[29]}$; (4) activation of high yield, high specific surface area. But there are three major disadvantages: (1) the large corrosion of equipment; (2) environmental pollution; (3) chemical activator remaining in the activated carbon products, limiting their practical application.

\section{Chemical Physics activation method}

Chemical physical activation method refers to using chemical activator to impregnate carbonaceous raw material, and then through the physical activation prepared quality activated carbon. The biomass activated carbon prepared by using this method has a specific pore distribution, and the number of pores has a significant increase.

T.Budinova, et al. ${ }^{[30]}$ used sawdust as raw material, used phosphoric acid and steam joint activation prepare high-performance activated carbon, having a specific surface area of $1360.0 \mathrm{~m} / \mathrm{g}$, and the iodine adsorption value is $1280.0 \mathrm{mg} / \mathrm{g}$. X.X. Yang, et al. ${ }^{[31]}$ used charcoal as raw material, first impregnated with potassium hydroxide, and then used water steam activation method, the sample is carbonized after washing with distilled water, to obtain better performance of activated carbon, the adsorption of methylene blue value is $409 \mathrm{mg} / \mathrm{g}$, BET specific surface area is $943 \mathrm{~m}^{2} / \mathrm{g}$.

\section{The research on modified method of biomass activated carbon}

\section{The modification of the surface physical structure characteristics}

The modification method of surface physical structural characteristics of activated carbon is mainly using physical or chemical methods to increase the surface area of activated carbon, and adjust its pore size distribution (enlarged or reduced pore size), thereby enhancing its physical adsorption properties.

Pore adjustment is to make pore size distribution of activated carbon more uniform, and allow the size is fitting to the adsorbate molecular size, improve the adsorption properties of activated carbon. By adding some activator during the activation process to control the degree of activation can reach openings, expanding and creating new holes purposes. In order to achieve the shrinkage purpose, generally use heat shrinkable, gas hot plugging holes, dip overlay and other methods ${ }^{[32]}$.

\section{The modification of the surface chemical characteristics}

The modification of the surface chemical characteristics of activated carbon is through some chemical or physical methods, to change the surface functional groups and ions or compounds on surface load of activated carbon, to become an active point on the substance adsorption process, so as to control hydrophilic performance, as well as with a metal (or metal oxide) binding capacity. Due to the differences in the chemical composition of the activated carbon surface, the acid alkali 
properties, the catalytic properties and the adsorption selectivity of activated carbon are different ${ }^{[33]}$. Commonly used modification method: surface oxidation modification, surface reduction modification method, load metal modification method and acid alkali modification method, etc.

\section{Surface oxidation modification}

Surface oxidation modification means: at a certain temperature, select the appropriate oxidizing agent to process the activated carbon surface functional groups, increasing the number of carbon surface oxygen-containing acid groups, to improve its adsorption capacity on polar substances. Commonly used oxidants are mainly $\mathrm{HNO}_{3}{ }^{[34]}, \mathrm{O}_{3}, \mathrm{HClO}_{4}$ and $\mathrm{H}_{2} \mathrm{O}_{2}$, etc. Using different oxidants to treat activated carbon, the number and type of oxygen-containing functional groups of activated carbon surface is different, its quantity increases as the degree of oxidation increasing ${ }^{[35]}$. Activated carbon modified by oxidation, itself corresponding changes in the pore structure, specific surface area and pore volume of activated carbon drop, pore of activated is larger. In addition, in the modified process, using the high-temperature treatment to remove the activated carbon surface acidic groups (carboxyl group, etc.), the porous change produced by oxidation will not be affected.

\section{Surface reduction modification}

Surface reduction modification mainly refers to: at the appropriate temperature, using an appropriate reducing agent to restore the surface functional groups of activated carbon, increasing the number of carbon surface oxygen-containing basic group and enhance its non-polar surface, making it adsorption capacity of the non-polar substances stronger. Commonly used reducing agents include $\mathrm{H}_{2}, \mathrm{~N}_{2}, \mathrm{NaOH}, \mathrm{KOH}$, and ammonia, etc. In the treatment process, the activated carbon after reduction treatment, the number of oxygen-containing basic groups on its surface increased significantly, in favor of activated carbon for certain pollutants (especially organic pollutants) adsorption ${ }^{[36]}$.

\section{Load metal modification}

Load metal modification refers to because of activated carbon's reduction and adsorption, the metal ions preferentially load to the activated carbon surface, which is then reduced to elemental, or low valence ions, using the combination of a metal or metal ions with the adsorbate, to enhance the adsorption capacity of activated carbon. Nowadays, copper ions, iron ions, etc are commonly used load metal ions ${ }^{[37]}$. Due to the presence of the metal in the activated carbon surface, reducing the regeneration temperature of the activated carbon, the regeneration efficiency of activated carbon can be improved. Further, the activated carbon as the catalyst carrier, it can be completely combusted, reducing the cost of recovery of the metal; there will be no secondary pollution.

\section{Acid alkali modification}

Acid alkali modification is using acid, alkali and other substances to modify activated carbon. Based on actual demand, researchers could adjust the carbon surface functional groups to meet the required amount and obtain a high-performance activated carbon. By acid alkali modification, it can improve the adsorption capacity of activated carbon to metal ions (copper ions as the representative), and also can ease less varieties of conventional activated carbon, functional quality is not high. Acid and alkali reagents commonly include $\mathrm{HNO}_{3}{ }^{[38]}, \mathrm{HCl}, \mathrm{NaOH}$, citric acid ${ }^{[39]}$ and ammonia, etc. Using acid alkali modifier to treat activated carbon, the adsorption capacity of activated carbon to some organics can be increased. L.D. Zhang, et al. ${ }^{[40]}$ used acid alkali reagent to modify activated carbon, their study shown that it removing the acid, alkali-soluble substances of activated carbon surface, reducing charcoal ash, increasing the surface area of activated carbon to improve its adsorption activity, the adsorption of benzene improved significantly.

\section{The electrochemical properties modification}

The electrochemical properties of the activated carbon surface determines its size of itself adsorption capacity, including physical adsorption and chemisorption. Activated carbon is composed of graphite crystallites and amorphous carbon, with good electrical conductivity. Because 
it can capture charges, activated carbon surface has a certain amount of charge ${ }^{[41]}$. Electrochemical modification means under the action of activated charcoal micro electric field, changing their surface chemical properties, to improve the adsorption capacity and adsorption selectivity.

Y.P. Guo ${ }^{[42]}$ has been studied on electrical adsorption treatment chloroform aqueous solution... The study found that with the potential of activated carbon increasing, the adsorption capacity of chloroform gradually increases, but also to accelerate the absorption rate, anodic polarization is good for the activated carbon adsorption for chloroform, cathodic polarization inhibit the activated carbon adsorption for chloroform.

\section{Conclusion and prospects}

(1) Use of waste raw materials for preparing activated charcoal not only solve the problems of waste biomass occupation of land resources and polluting the environment, reduce the cost of production of activated carbon produced, but also to meet the social demand of the great number of activated carbon.

(2) The surface physical structure characteristics of modified activated carbon improved the adsorption capacity of activated carbon. The adsorption capacity of different substances onto activated carbon can be enhanced by Surface oxidation modification method or surface reduction modification method. Metal ion load and acid alkali modification could improve the adsorption capacity of activated carbon for certain substances (elements or ions).

(3) The electrochemical modification method will not cause secondary pollution to the environment, and it is lower energy consumption and easy to operate. In additional, the regeneration of electrochemical modification of activated carbon can achieve integration operation. Therefore, the development direction of future research of biomass activated carbon is electrochemical modification method.

\section{Acknowledgments}

This paper has greatly benefited from the insightful comments of two anonymous reviewers. We are grateful to the Natural Science Foundation of China (NO.21367010) and The Special Funding for Guangxi'BaGui Scholar'Constuction Projects.

\section{References}

[1]R.M. Suzuki, A.D. Andrade and J.C. Sousa: 'Preparation and characterization of activated carbon from rice bran’, Bioresour. Technol., 2007, 98(10), 1985-1991.

[2]L.G. Liu, J. Chen and Q.Q. Xia: 'The preparation method of activated carbon from chestnut shell’, Hubei. Agri. Sci., 2008, 47(3), 337-339.

[3]B. Han, M.H. Zhou and D. Rong: 'The preparation and characterization of the straw stalk activated carbon’, J. Agro-Environ. Sci., 2009, 28(4), 828-832.

[4]Y.X. Wang, C.M. Liu and Y.P. Zhou: 'Preparation of mesopore-enriched bamboo activated carbon and its adsorptive applications study’, J. Func. Mater. 2008, 39(3), 420-423.

[5]B. Li and N.X. Xu: 'Long handle almond shell activated carbon prepared by zinc chloride activation method', J. Northwest. U. (nat. sci. ed.), 2010, 40(5), 806-810.

[6]Y.B. Tang, Q. Liu and F.Y. Chen: 'Preparation and characterization of activated carbon from waste ramulus mori’, Chem. Eng. J., 2012,203, 19-24.

[7]C.X. Cui, C.D. Si and Q.J. Guo: 'Preparation and decolorization properties of activated carbon straw’, J.Qingdao. univ. Sci.Technol., 2010,31(1), 42-46.

[8]D. Li: 'Preparation, forming and activation mechanism of biomass charcoal research', MA thesis, 
Yantai University, Shandong, CN, 2013.

[9]B.L. Chen and Z.M. Chen: 'Sorption of naphthalene and 1naphthol by biochars of orange peels w fferent pyrolytic temperatures', Chemosphere, 2009,76, 127-133.

[10]Z.L. An, Y.W. Hou and C. Cai: 'Rice straw biochar adsorption characteristics on $\mathrm{Pb}$ ( II )research’, J. Eng. Chem., 2011,30(11), 1851-1857.

[11]J.N. Sahu, Acharya, Jyotikusum and B.C. Meikap: 'Optimization of production conditions for activated carbons from Tamarind wood by zinc chloride using response surface method logy', Bioresour. Technol., 2010, 101(6), 1974-1982.

[12]M.S. Lou: 'Preparation of biomass charcoal and activated carbon adsorption of phenol wastewater research’, MA thesis, Hefei University, Anhui, CN, 2013.

[13]D.S. Zhang and C.J. Deng: 'Effect of carbonization temperature on the structure and electrochemical properties of bamboo-based charcoal hole’, Forest Prod. Ind., 2010,37(3), 57-62.

[14]Z.X. Zhang, J. Wu and J. Meng: 'Research on carbonised process characteristics of biomass', Mater. Res. Innovations, 2014, 18(S5), 79-81.

[15]N.N. Hu and F. Fu: 'Wood high temperature carbonization and conducting function of charcoal research progresses, Wor. Forest. Res., 2010, 23(4), 51-55.

[16]C.J. Chen: 'Preparation of activated carbon by microwave radiation agriculture and forestry waste research progress’, Int. Mater. Rev., 2007, 21(11A), 291-294.

[17]G.Z. Wang, L.X. Li and Y.Z. Li: 'Study on preparation of bamboo charcoal and adsorption of phenol-containing waste water’, J. Chem. Eng. CU., 2010, 24(4), 700-704.

[18]A. Arami-Niya, W.M.A.W. Daud and F.S. Mjalli: 'Comparative study of the textural characteristics of oil palm shell activated carbon produced by chemical and physical activation for methane adsorption’, Chem. Eng. Res. Des., 2011,89(6), 657-664.

[19]H.Y. Xia: 'Preparation and analysis of high-quality charcoal mechanism', MA thesis, Kunming University of Technology, Kunming, CN, 2006.

[20]K.B. Yang, J.H. Peng and H.Y. Xia: ' $\mathrm{CO}_{2}$ activation preparation of coconut shell based activated carbon’, Carbon Technol., 2010, 29(1), 20-23.

[21]K. Sun and J.C. Jiang: 'Preparation and characterization of activated carbon from rubber-seed shell by physical activation with steam’, Biomass Bioenergy., 2010, 34(4), 539-544.

[22]O. Sahin and C. Saka: 'Preparation and characterization of activated carbon from acom shell by physical activation with $\mathrm{H}_{2} \mathrm{O}-\mathrm{CO}_{2}$ in two-step pretreatment', Bioresour. Technol., 2013,136, 163-168.

[23]B.B. Zhang, Y.Q. Liu and Y.Y. Ye: 'Preparation of activated carbon and its activation mechanism research progress’, J. Mod. Chem. Ind., 2014, 34(3), 34-39.

[24]Y.B. Ji, T.H. Li and L. Zhu: 'Preparation of activated carbons by microwave heating $\mathrm{KOH}$ activation’, Appl. Sur. Sci., 2007,254 (2), 506-512.

[25]A.A. Attia, B.S. Girgis and N.A. Fathy: 'Removal of methylene blue by carbons derived from peach stones by $\mathrm{H}_{3} \mathrm{PO}_{4}$ activation: batch and column studies', Dyes Pig., 2008, 76(1), 282-289.

[26]A.H. Basta, V. Fierro and H. Elsaied: '2-Steps KOH activation of rice straw: an efficient method for preparing high-performance activated carbon', Bioresour. Technol., 2009, 100(17), 3941-3947.

[27]K. Sun and J.C. Jiang: 'Abandoned bamboo preparation of high specific surface area activated 
carbon and its performance study’, J. Mod. Chem. Ind., 2009, 29(S2), 178-181,183.

[28]A.A. Elhendawy, A.J. Alexander and R.J. Andrews: 'Effects of activation schemes on porous surface and thermal properties of activated carbons prepared from cotton stalks', Anal. Appl. Pyroly., 2008, 82(2), 272-278.

[29]S.L. Zuo, J.L. Liu and J.X. Yang: 'Effect of phosphoric acid activation method of activated carbon properties of methylene blue adsorption capacity’, Forest Prod. Chem. Ind., 2010, 30(4), $1-6$.

[30]T. Budinova, E. Ekinci and F. Yardim: 'Characterization and application of activated carbon produced by $\mathrm{H}_{3} \mathrm{PO}_{4}$ and water vapor activation’, Fuel Process. Technol., 2006, 87, 899-905,

[31]X.X. Yang and Y.T. Zhang: 'Physical-chemical coupling activation of coal based activated carbon', Coal Conver., 2009, 32(2), 66-70.

[32]X. Jiang, W.J. Jiang and Y. Jin: 'Modified activated carbon in Environmental Protection application’, Environ. Sci. Technol., 2002, 26(5), 55-57.

[33]J.S. Bae and D.D. Do: 'Surface Diffusion of Strongly Adsorbing Vapors in Activated Carbon by a Differential Permeation Method', Chem. Eng. Sci., 2003,58(19), 4403-4415.

[34]N. Wibo, wo, L. Setyadhi and D. Wibo, wo: 'Adsorption of benzene and toluene from aqueous solutions onto activated carbon and its acid and heart treated forms: Influence of Surface chemistry on adsorption', J. Hazard. Mater. 2007, 146(1-2), 237-242.

[35]W.B. Fan, H.Q. Yin and J.X. Guo: 'Activated carbon modified method research', In 2012 China Environmental Science Institute Annual Conference Proceedings. Beijing: China Agricultural University Press, 2012, 2262-2266.

[36]W. Su, T.P. Zhou and L.F. Wei: 'Effect of micro-structure and surface modification on the hydrogen adsorption capacity of active carbons’, New Carbon Mater., 2007, 22(2), 135-140.

[37]J. Paul, Chen and Shunnian Wu: 'Simultaneous adsorption of copper ions and humic acid onto an activated carbon', J. Colloid Interface Sci., 2004, 280(2), 334-342.

[38]L.Q. Li and X. Liang: 'Acid-modified activated carbon on adsorption performance for toluene methanol’, J. Chem. Ind., 2013, 64(3), 970-979.

[39]J. Paul, Chen, S.N. Wu and K.H. Chong: 'Surface modification of a granular activated carbon by citric acid for enhancement of Copper adsorption’, Carbon, 41(10), 2003, 1979-1986.

[40]L.D. Zhang, X.P. Zhao and Q. Ma: 'Modified activated carbon to benzene waste gas adsorption study’, New Carbon Mater., 2002, 17(2), 41-44.

[41]B.K. Kim, S.K. Ryu and B.J. Kim: 'Adsorption behavior of propylamine on activated carbon fiber surfaces as induced by oxygen functional complexes’, J. Colloid Interface Sci., 2006, 302(2), 695- 697.

[42]Y.P. Guo: 'Activated carbon electricity adsorption treatment of chloroform in water research', MA thesis, Northeast Normal University, Changchun, CN, 2002.

ith di 